Área: Ciencias de la Salud

Disciplina: Medicina

Tipo de artículo: Reporte de caso

\title{
Complicaciones graves de neumonía en lactante mayor, a propósito de
}

\author{
un caso
}

\section{Autores}

Capa Carrillo Diana ${ }^{\mathbf{a}} \mathbf{b}$, Herrera Viniachi Inés $\mathbf{a}, \mathbf{b}$, Martha Zambrano a, b.

\section{Afiliación institucional}

a. Universidad Católica de Santiago de Guayaquil.

b. Hospital Roberto Gilbert Elizalde.

\section{Correspondencia}

Diana Capa Carrillo, Posgrado de Pediatría. dra.dianacapa@outlook.com

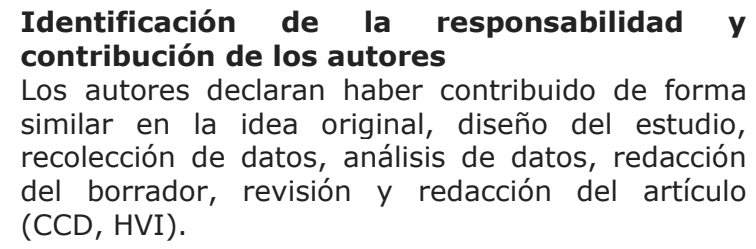

\section{Resumen}

La neumonía adquirida en la comunidad es una de las principales causas de morbilidad en los países desarrollados, y es la primera causa de mortalidad infantil en el mundo. Los virus respiratorios son los más frecuentes en toda la edad pediátrica exceptuando el periodo neonatal. Entre las principales complicaciones de las NAC tenemos: derrame pleural paraneumónico (DPP), empiema pulmonar (EP); neumotórax, fístula broncopleural (FBP), absceso pulmonar (AP), neumonía necrosante o necrotizante $(\mathrm{NN})$ y pioneumotórax; su diagnóstico etiológico se logra en el $40 \%$ de los casos, siendo el neumococo la bacteria más frecuentemente aislada.

En pediatría representan una causa frecuente de hospitalización, siendo el derrame pleural una complicación frecuente, que requiere de manejo oportuno y adecuado. El presente reporte describe la presentación clínica, complicaciones y manejo de una neumonía complicada.

Palabras clave: derrame pleural; empiema; pulmón; neumotórax. 
Serious complications of pneumonia, in an older infant, about a case

\section{Abstract}

Community-acquired pneumonia is a major cause of morbidity in developed countries and is the leading cause of child mortality in the world. Respiratory viruses are the most common in all pediatric age groups except the neonatal period. Among the main complications of CAP are: parapneumonic pleural effusion (PPD), pulmonary empyema (PE); pneumothorax, bronchopleural fistula $(P B F)$, pulmonary abscess $(P A)$, necrotizing or necrotizing pneumonia (NP) and pioneumothorax; its etiological diagnosis is made in $40 \%$ of cases, being pneumococcus the most frequently isolated organism.

In paediatrics these diseases represent a frequent cause of hospitalization, being pleural effusion a frequent complication, which requires timely and adequate management. This report describes the clinical presentation, complications, and management of complicated pneumonia.

Keywords: pleural effusion; empyema; lung; pneumothorax;

\section{Introducción}

Las complicaciones de las neumonías se producen cuando la infección no se limita al parénquima pulmonar, sino que se extiende a áreas vecinas, o cuando el desarrollo de la infección es más complejo que el habitual por diferentes motivos. Esto modifica el curso clínico de la neumonía inicial, constituyendo a la infección pleuropulmonar en un reto para su adecuado manejo, ya que no hay unificación en los criterios de clasificación lo que puede llevar a una confusión, retraso en la toma de decisiones y a una oportuna y adecuada intervención. ${ }^{1-3}$

Las mayores complicaciones de la neumonía incluyen: neumotórax, (fístula broncopleural), neumonía necrosante y

\section{Abstrato}

A pneumonia adquirida na comunidade é uma das principais causas de morbidade nos países desenvolvidos, e é a principal causa de mortalidade infantil no mundo. Os vírus respiratórios são os mais comuns em todas as faixas etárias pediátricas, exceto no período neonatal. Entre as principais complicações da PAC estão: derrame pleural parapneumônico (DPP), empiema pulmonar $(E P)$; pneumotórax, fístula broncopleural (PBF), abscesso pulmonar (AP), pneumonia necrosante ou necrosante (NP) e pneumonia pioneira; seu diagnóstico etiológico é feito em $40 \%$ dos casos, sendo o pneumococo o organismo mais freqüentemente isolado.

Na pediatria estas doenças representam uma causa freqüente de internação hospitalar, sendo a efusão pleural uma complicação freqüente, o que requer um manejo adequado e pontual. Este relato descreve a apresentação clínica, as complicações $e$ o manejo da pneumonia complicada.

Palavras-chave: derrame pleural; empiema; pulmão; pneumotórax.

empiema. Las últimas dos parece que han ido incrementando. La neumonía necrosante (NN) se puede sospechar por radiología, pero usualmente se diagnostica por tomografía. En las últimas décadas se han observado cambios epidemiológicos con un aumento de la prevalencia de este tipo de complicaciones de las neumonías. También se ha observado cambios en la prevalencia de gérmenes y serotipos que se lo relaciona con el uso más racional de antibióticos y los cambios en la estrategia vacunal.

La frecuencia de los distintos gérmenes en todos los grupos de edad pediátrica, según diversas series, es la siguiente: Staphylococcus aureus el 35 \% (en lactantes 


\section{Salud, Naturales, Sociales y Formales}

el $50 \%)$, Streptococcus pneumoniae el 35 $\%$, Streptococcus spp. el $15 \%$, Haemophilus el $5 \%$, Pseudomonas el $5 \%$, anaerobios el 5 $\%$. Existen otras causas de DPP: virus (adenovirus, influenza, parainfluenza), Mycoplasma pneumoniae y Mycobacterium tuberculosis. 1-4

\section{Caso clínico}

Paciente con antecedente de nacimiento por dilatación estacionaria a las 39,5 semanas, madre indica que no hubo llanto inmediato, que requirió oxígeno y permaneció hospitalizada por 1 semana con diagnóstico de neumonía, recibiendo dos esquemas de antibiótico primero a dosis terapéutica (amoxicilina $75 \mathrm{mg} / \mathrm{kg}$ día por 3 días), el segundo a dosis infraterapéutica (cefuroxima $18,5 \mathrm{mg} / \mathrm{kg} /$ día por 2 días), permaneció hospitalizada por 2 días requiriendo oxigenoterapia, con inmunizaciones completas para la edad y antecedentes familiares de padres y tíos paternos asmáticos.

Acude a valoración por cuadro clínico caracterizado por alza térmica persistente cuantificada hasta $40,9^{\circ} \mathrm{C}$, que cedía momentáneamente con antipiréticos y rinorrea hialina, por lo cual acude a centro salud a las 24 horas, siendo medicada con antibióticos, antipiréticos, sin mejoría clínica, acompañándose de tos no productiva que evoluciona a húmeda, no cianosante, rubicundizante, en ocasiones emetizante acompañada de dificultad respiratoria caracterizado por aumento del patrón respiratorio, por lo que es llevada al cuarto día al Hospital MSP Darío Machucha de La Troncal, donde fue hospitalizada y medicada con antipiréticos intravenosos, oxigenoterapia y nebulizaciones, siendo dada de alta a las 48 horas, pero cuadro clínico persistía con dificultad respiratoria y fue referido a nuestra institución. Al examen físico se presenta paciente taquicárdico, taquipneico, pálido, irritable con signos de dificultad respiratoria, a la auscultación campos pulmonares medio y basal derecho hipoventilados y rales en hemitórax izquierdo.

Dentro de los resultados de los paraclínicos, en cuanto a las imágenes se evidenció en la radiografía de tórax una imagen sugestiva de derrame pleural derecho; en la tomografía de tórax se observó una gran colección pleural derecha que colapsa parcialmente el pulmón y que presentan además imágenes de broncograma aéreo en relación a consolidación pulmonar, con una pequeña área del pulmón derecho en el segmento anterior del lóbulo superior e inferior funcional, desplazamiento del mediastino por derrame pleural y la presencia de formaciones cavitarias, probablemente neumatoceles, en el lóbulo superior derecho, el pulmón izquierdo presentó discreta consolidación pulmonar en los segmentos basales posteriores. Con respecto con los resultados de laboratorio, a su ingreso presentó anemia microcítica sin repercusión hemodinámica, con hemoglobina de $7,6 \mathrm{mg}$, hematocrito en $23,4 \times 103 \mathrm{UI}$ requiriendo transfusión, tensiones arteriales dentro del percentil para su edad, leucocitosis de 14.500 , a predominio de los neutrófilos (51 $\%)$, Ziehl de aspirado gástrico negativo, hemocultivo con rescate de $S$. epidermidis, ADN-PCR TB no detectado, cultivo de líquido pleural sin crecimiento.

Dentro del manejo terapéutico se procedió con soporte de oxígeno por mascarilla de no reinhalación, pase a unidad de cuidados intensivos pediátricos para manejo con oxigenoterapia de alto flujo, controles gasométricos en equilibrio ácido base, así como manejo del enfisema subcutáneo derecho y neumotórax derecho (que requirió toracostomía con succión a $8 \mathrm{mmHg}$, durante 9 días, hasta retiro accidental); posterior al retiro accidental del tubo de toracostomía, presentó deterioro del patrón respiratorio con necesidad de oxigenoterapia de alto flujo.

Se le efectuó toracotomía y lobectomía de lóbulo superior derecho (necrosado), lóbulo medio e inferior tapizado de fibrina gruesa, (que no permitía expansión adecuada), permaneciendo en ventilación mecánica menos de 24 horas; posteriormente, se le colocó en oxigenoterapia de alto flujo por 4 días, seguido de 4 días con cánula nasal.

Ante datos de neumonía complicada (previa valoración por el servicio de Infectología), se inició esquema con ceftriaxona y clindamicina de forma empírica, posteriormente se decidió ampliar a vancomicina; ante datos de respuesta inflamatoria sistémica fue revalorado por el servicio de Infectología, que indicó rotar a cefepime, completando 21 días de tratamiento antibiótico.

En el caso de la paciente estudiada no fue posible determinar el agente microbiológico causal.

\section{Discusión}

La infección respiratoria baja sigue siendo una de las causas con alta mortalidad en niños menores de 5 años en países en vías de desarrollo ${ }^{3}$. La mayoría de los estudios epidemiológicos reporta como agente etiológico en mayores de 3 meses hasta los 5 años a Streptococcus pneumoniae, Staphylococcus aureus, algunos de ellos meticilino resistente, seguido por otras especies de Streptococcus (S.pyogenes, S. millery), anaerobios, Haemophilus influenzae tipo b, Pseudomona aeruginosa, Mycoplasma pneumonia y Mycobacterium tuberculosis. 


\section{Salud, Naturales, Sociales y Formales}

También los virus como el adenovirus y la influenza. ${ }^{1}$ Sin embargo, se describe en la literatura que el diagnóstico etiológico solo se logra en el $40 \%$ de los casos, siendo el neumococo la bacteria más frecuentemente aislada. ${ }^{3}$

Existen estudios en los cuales un elevado porcentaje de pacientes estaba con tratamiento antibiótico previo al diagnóstico, lo que puede explicar la baja tasa de positividad de los cultivos microbiológicos. 8 Durante la evolución de una neumonía no es infrecuente que los niños presenten complicaciones, tales como: derrame pleural paraneumónico, empiema pulmonar, absceso pulmonar, neumonía necrotizante y pioneumotórax. ${ }^{5,9}$

En los últimos años se ha evidenciado un aumento del número de hospitalizaciones por neumonía bacteriana y en la prevalencia de complicaciones en niños, sin determinarse aún cuál es la causa de este aumento en las complicaciones. Algunos autores sugieren que pueden deberse al aumento de la resistencia bacteriana sobre todo del neumococo, la presencia de determinados serotipos y la respuesta inflamatoria del huésped a los componentes del agente causal.

Varios estudios coinciden en la existencia de factores asociados una neumonía complicada como: edad (> 36 meses), uso de antibióticos antes de la hospitalización, formas inmaduras en sangre periférica, aumento PCR y trombocitopenia. ${ }^{3}$

En este paciente se puede evidenciar 4 de los 5 factores asociados a neumonía complicada, desarrollando neumonía con derrame paraneumónico, que evolucionó a neumonía necrotizante; desde 1990 se han reportado en varios países un aumento de las complicaciones supurativas de la neumonía adquirida en la comunidad, siendo las más frecuentes el empiema y neumonía necrotizante.

Se denomina neumonía necrotizante a la necrosis del parénquima pulmonar, frecuentemente se acompaña de otras complicaciones como insuficiencia respiratoria, fístula broncopleural, pioneumatoceles o neumotórax.

La infección del parénquima se manifiesta por la producción de una gran reacción inflamatoria con destrucción tisular y sustitución por cavidades llenas de aire (neumatoceles); en las zonas periféricas del pulmón la necrosis determina el desarrollo de fístulas broncopulmonares.

Diversos autores han encontrado como factores predictores de necrosis: mal estado general; fiebre que persiste o reaparece; neumonía multilobar; fístulas broncopleurales; cifra de glóbulos blancos menor a 5.000 o mayor a 30.000 elementos/ml y trombocitopenia en sangre periférica; lactato deshidrogenasa en líquido pleural mayor a $2500 \mathrm{UI} / \mathrm{L}$; proteína C reactiva mayor a $120 \mathrm{mg} / \mathrm{dl}^{2}$

De acuerdo con lo descrito, se puede observar que la paciente en estudio presentó la gran mayoría de los factores predictores para necrosis pulmonar y que evolucionó con demás complicaciones, como derrame pleural, neumatoceles y fístula broncopleural.

El manejo inicial de las complicaciones de la neumonía está dirigido a la administración de antibióticos específicos, a dosis altas dirigidos contra los gérmenes detectados en hemocultivo o en el cultivo del líquido pleural, pero en la mayoría de los casos no se tiene un cultivo que lo detecte en forma rápida o estos son negativos por la administración previa de antibiótico.

Se debe iniciar antibióticos de amplio espectro contra el neumococo y el $S$. aureus, que son los gérmenes más frecuentes, sin tardanza.

En caso de que los derrames comprometan el estado respiratorio del paciente se hace necesario el drenaje con una toracentesis simple o con un tubo de tórax.

La decisión de la intervención quirúrgica se debe tomar cuando falla el tratamiento conservador, y en los casos de loculación que no mejoren con el tratamiento fibrinolítico. Los procedimientos utilizados son: minitoracotomía, toracotomía con decorticación y la videotoracoscopia asistida. ${ }^{1}$

\section{Conclusiones}

En este caso a pesar de no haberse aislado un agente etiológico causal, desde el ingreso se brindó cobertura antibiótica empírica de acuerdo a la etiología más frecuente con antimicrobianos de amplio espectro como lo describe la literatura; sin embargo, por la evolución tórpida tanto clínica, como de imagen, se efectuó videotoracoscopia más decorticación en primera instancia, con posterior necesidad de toracotomía ampliada más lobectomía de lóbulo superior derecho, con lo que se obtuvo remisión de los síntomas y se logró el egreso en condiciones estables.

Las neumonías en pediatría representan una causa frecuente de hospitalización, siendo el derrame pleural una frecuente complicación, el cual debe ser manejado oportuna y adecuadamente con antibióticos de acuerdo con la bacteriología local y grupo etario, si el derrame está tabicado la mejor recomendación es una videotoracoscopía que mejore al niño en menor tiempo y con menos secuelas. 
A pesar de recibir el antibiótico apropiado, no siempre se obtiene una adecuada respuesta al tratamiento requiriendo manejo más agresivo como en este caso.

\section{Referencias}

1. Bertha Agudelo, Neumonía complicada en pediatría, su manejo: un reto, Colombia 2013; 8 (2): 79-85.

2. Karina Machado, Neumonía necrotizante en niños hospitalizados en el Hospital Pediátrico- Centro Hospitalario Pereira Rossellen el año 2010, Uruguay 2013; 84(2): 101-110.

3. María José Guerdile, Complicaciones respiratorias asociadas a la neumonía bacteriana, Buenos Aires Vol. 2: 42008.

4. Juana María Rodríguez Cutting, Neumonía complicada adquirida en la comunidad: Resolución de los hallazgos clínicos y radiológicos en niños, La Habana, Cuba, 2015;14(4):438-446.

5. Anselmo Andrés Martín, Complicaciones de la neumonía adquirida en la comunidad: Derrame pleural, Neumonía necrotizante, absceso pulmonar y pioneumotórax, Barcelona 2017;1:127-146.

6. Odalys Cáceres Roque, Comportamiento de las neumonías complicadas en niños en hospital pediátrico provincial pinareño, Pinar del Río, Cuba 2018; 22(6): 1044-1052.

7. F.J. Aracil Santos, Mesa Redonda: Infección neumocócica desde distintas perspectivas, Madrid 2008; 48: 183-188.

8. B. Espínola Docio. Derrame pleural en niños con neumonía. Estudio de 63 casos. Unidad de Cuidados Intensivos Pediátricos. Hospital del Niño Jesús. Madrid. España. An Pediatr (Barc). 2008;69(3):210-4.

9. Bernardita Chateau. Neumonía complicada con neumatocele en un lactante, caso clínico. Rev Chil Pediatr 2008; 79 (3): 295-30. 